\title{
Case series: Transplantation of kidneys from donors with renal artery aneurysm
}

\author{
Mahmoud Alameddine, MD'; Zhobin Moghadamyeghaneh, MD'; Giselle Guerra, MD'; Mahmoud Morsi, MD'; \\ Mohammed Osman, MD'; V.J. Chia, MD'; George W. Burke, MD'; Linda Chen, MD'; Rodrigo Vianna, MD'; \\ Ian Zheng"; Javier González, MD'; Gaetano Ciancio, MD'
}

'Department of Transplant Surgery, University of Miami Miller School of Medicine, Miami, FL, United States; ${ }^{2}$ University of Miami Miller School of Medicine, Miami, FL, United States; ${ }^{3}$ Hospital Central de la Cruz Roja Universidad Alfonso X El Sabio, Spain

Cite as: Can Urol Assoc J 2017;11 (7):E307-10. http://dx.doi.org/10.5489/cuaj.4244 Published online July 11, 2017

\section{Abstract}

Introduction: With the present disparity between organ availability and recipient demands, we reported our experience in transplanting kidneys with renal artery aneurysm after back-table reconstruction. Methods: Four patients were identified. The repair consisted of excision of the aneurysm with ostial closure, and for one of the cases, an ovarian vein patch was used. We reviewed the safety and outcomes of this procedure. All donors were asymptomatic before surgery and were diagnosed incidentally during living donor evaluation. The nephrectomies performed were hand-assisted laparoscopic approaches. All recipients had followup renal function and ultrasound duplex of renal artery at six and 12 months and then annually.

Results: The mean age of the recipients was 28.7 years (range 3-45). The mean size of the aneurysm was $7.4 \pm 2.7 \mathrm{~mm}$. All patients had immediate graft function with median serum creatinine of $1.9 \pm 1.5$ $\mathrm{mg} / \mathrm{dL}$ at discharge. The average length of hospital stay was $6.25 \pm$ 2.6 days. They also maintained good renal function with an average estimated glomerular filtration rate (eGFR) of $102.8 \mathrm{~mL} / \mathrm{min} / 1.73 \mathrm{~m}^{2}$ (range $53.4-199 \mathrm{~mL} / \mathrm{min} / 1.73 \mathrm{~m}^{2}$ ) and patent vessels at one year. One patient suffered from acute antibody-mediated rejection and lost his graft (medication non-compliance). One patient had two simultaneous benign renal cysts that were resected. Three of the kidneys were right-sided and one left. Mean cold ischemia time was $86 \pm 18$ minutes. No deaths have been recorded.

Conclusions: Transplanting kidneys with a renal artery aneurysm after ex-vivo repair is safe and the outcomes are encouraging. Also, it may play an important role in expanding the donor pool in the face of current organ shortage.

\section{Introduction}

Renal artery aneurysm (RAA) is a rare condition; the incidence of RAA is $0.7 \%,{ }^{1}$ with autopsy studies indicating the incidence range to be $0.01-0.09 \% .^{2}$ Most commonly, it is asymptomatic and diagnosis is made incidentally during evaluation of different conditions, such as living donor workup. ${ }^{3}$ The question is whether to use such kidneys for transplant or not. In centres with large kidney transplant volume, it is not uncommon to face this debatable scenario. According to the U.S. Organ Procurement and Transplantation Network and the Scientific Registry of Transplant Recipients (OPTN/SRTR) Annual Data Report in 2013, the total number of patients waiting for a kidney transplant is 96 607. Median waiting times for adults increased from three years in 2003 to more than 4.5 years in $2009 .{ }^{4}$ In order to increase organ availability, we evaluated the feasibility of kidney transplantation from living donors with RAA.

\section{Methods}

We retrospectively reviewed the electronic records of all living donor nephrectomies from 2009-2015. Four patients were identified with RAA who underwent reconstruction of the allograft during back-table preparation. The safety and outcomes of the procedure were assessed in terms of allograft function and renal artery patency, the length of hospital stay, donor and recipient perioperative complications, and graft survival. All donors were incidentally diagnosed with saccular type RAA via abdominal computed tomography (CT) angiography (Fig.1). The contralateral kidneys and vasculature were normal in all donors. The nephrectomies performed were hand-assisted laparoscopic surgeries. The risks of surgery and potential complications were explained to both donors and recipients. Informed consent was taken from every patient. The study was approved by the institutional review board. One donor also had two simultaneous benign renal cysts, which were resected during the backtable preparation. After surgery, all recipients had followup renal function and ultrasound duplex (USD) of the renal artery at six and 12 months and then annually. Donors were followed up for two years after donation, as per OPTN/ UNOS policy. 


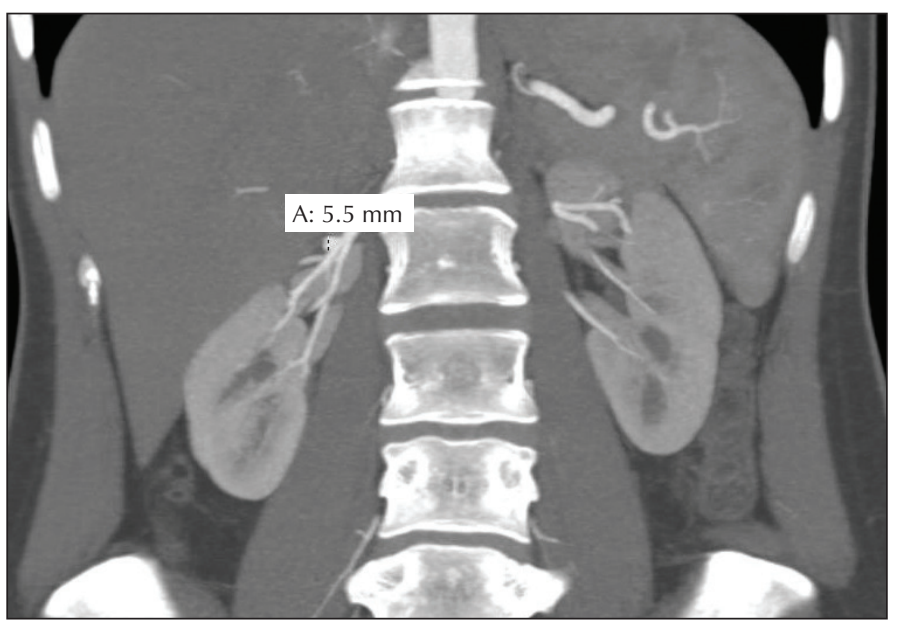

Fig. 1. Computed tomography angiography coronal section of donor showing a saccular type aneurysm at the bifurcation of the right renal artery.

All recipients received induction immunosuppression of thymoglobulin $(1 \mathrm{mg} / \mathrm{kg})$ along with methyl prednisolone (500 mg intravenous) for three daily doses and basiliximab (20 mg) for two doses. The patients were maintained on steroid-free immunosuppression regimen with low-dose tacrolimus (target 12 hours trough level: $4-6 \mathrm{ng} / \mathrm{ml}$ ) and enteric-coated mycophenolate sodium (720 mg) twice daily.

\section{Surgical technique}

\section{Laparoscopic nephrectomy}

Three patients underwent right hand-assisted laparoscopic nephrectomy and one patient underwent left nephrectomy. The patients were placed in semidecubitus position. Then, their chest and abdomen were prepped and draped. An 8 $\mathrm{cm}$ midline incision was made starting $2 \mathrm{~cm}$ above and through the umbilicus. Subsequently, a Gelport ${ }^{\circledR}$ with $10 \mathrm{~mm}$ port was placed for the surgeon's hand to gain access to the abdominal cavity. Two $5 \mathrm{~mm}$ trocars were placed thereafter. One was at the midclavicular line subcostally and the other was halfway between the umbilicus and the anterior superior iliac spine. The colon was initially mobilized medially. The ureter was dissected to the level of the common iliac artery. The kidney was freed from its surrounding tissue inferiorly, laterally, and superiorly. Then, the hilum was cleared and exposed. The aneurysm was identified. Vascular staplers were used to ligate and cut the ureter, renal artery, and vein successively. The specimen was handed on ice to the back-table for preparation. The port incisions were then closed. All allografts were transplanted in the right iliac fossa in the retroperitoneal space. The ureter was anastomosed with Lich-Gregoir extravesical antireflux technique.

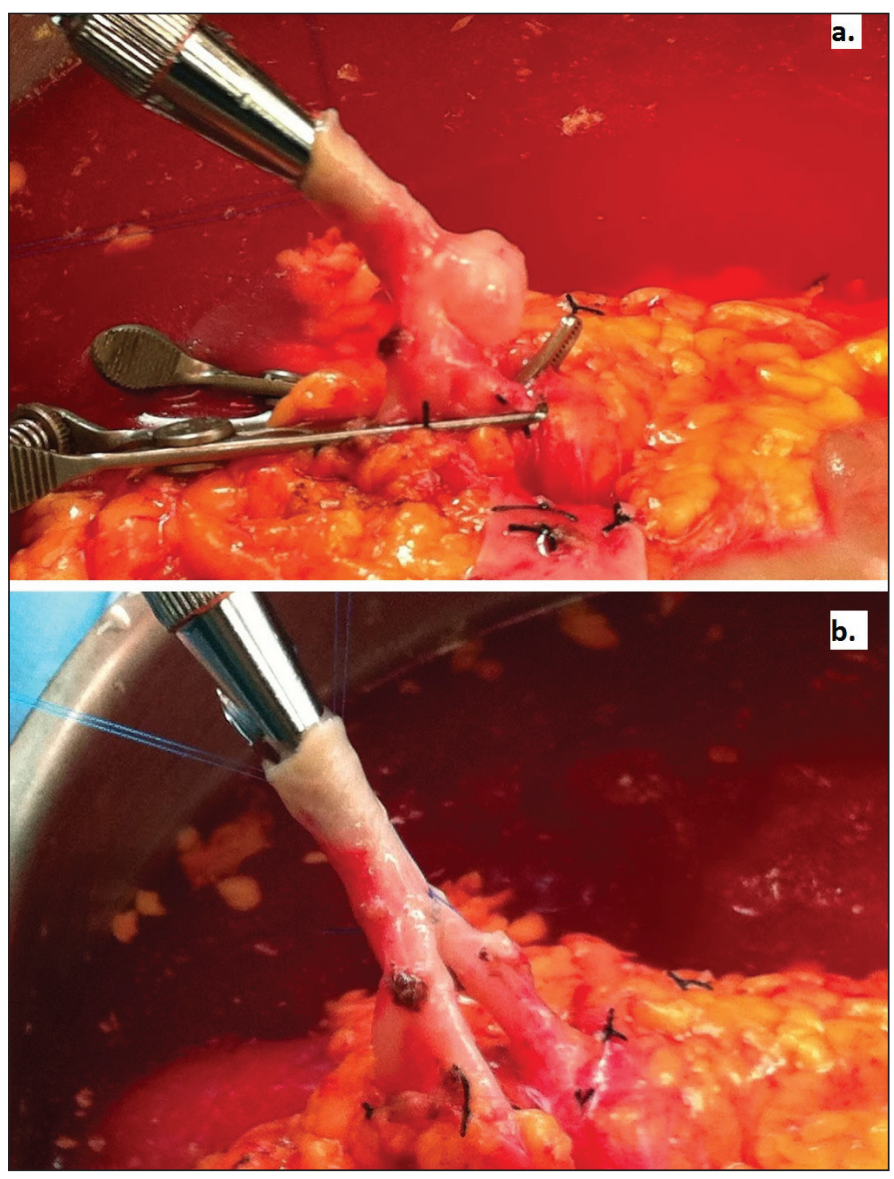

Fig. 2. (a) Saccular type renal artery aneurysm; and (b) excision of the aneurysm with primary closure.

\section{Back-table reconstruction}

The allograft was brought to the recipient operating room. During this stage of operation, the kidney was flushed with an ice-cooled mixture of lactated ringer solution and mannitol until the output was clear. First, the renal vein was dissected into the hilum and small branches were ligated. After that, the artery was cleaned up to the hilum. The aneurysm was identified and excised at its ostium using fine scissors (Fig. 2). The edges of the arterial defect were approximated with $7 / 0$ Prolene ${ }^{\circledast}$ suture in running fashion (Fig. 3). In one case, a segment of the donor gonadal vein was incised longitudinally and wrapped over the reconstructed renal artery to reinforce the site of repair. Then the edges of the venous patch were sewn with 7/0 Prolene in running fashion (Fig. 4).

\section{Results}

From 2009-2015, 584 kidney transplants were performed from living donors. We identified four allografts with RAA. All donors were asymptomatic at the time of evaluation. No chronic diseases (e.g., hypertension) or any other donor 

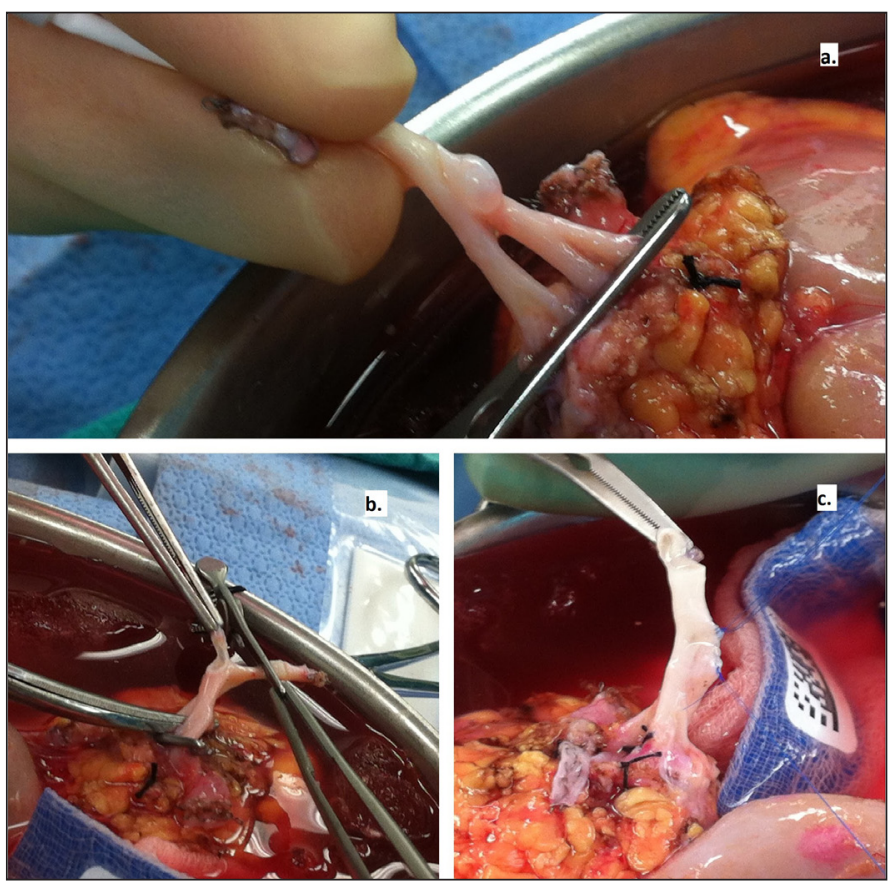

Fig. 3. Preparation of the kidney allograft in ice slash at the back-table.

risks were reported. Mean donor age was $44.5 \pm 15$ years, while recipient age was 28.7 years (range $3-45$ ). The donors were two males and two females (Table 1). The mean size of the aneurysm was $7.4 \pm 2.7 \mathrm{~mm}$. The donor operation was uneventful. All donors were discharged home on the second day after the operation with normal renal function and average serum creatinine at one year of $1 \pm 0.2 \mathrm{mg} / \mathrm{dL}$. All recipients had immediate graft function with mean serum creatinine of $1.9 \pm 1.5 \mathrm{mg} / \mathrm{dL}$ at discharge (Table 2). The cause of their renal failure ranged from lupus nephritis, multicystic dysplastic kidneys (Joubert syndrome), hypertension, and obstructive uropathy. One patient suffered from severe hypertension that improved post-transplant. The average length of hospital stay was $6.25 \pm 2.6$ days. The median followup time was 2.5 years. All maintained good renal function and patent renal vessels during the followup period except for one patient who lost his allograft due to acute antibody-mediated rejection (medication non-compliance). Mean estimated glomerular filtration rate (eGFR) at one year was $102.8 \mathrm{~mL} / \mathrm{min} / 1.73 \mathrm{~m}^{2}$ (range $53.4-199 \mathrm{~mL} / \mathrm{min} / 1.73 \mathrm{~m}^{2}$ ). The mean cold and warm ischemia times were $86 \pm 18$ minutes and $50 \pm 20$ minutes, respectively. No deaths have been recorded.

\section{Discussion}

A RAA is a dilated segment of renal artery that is more than twice the diameter of a normal renal artery. ${ }^{5}$ Roughly, RAAs are saccular in $62 \%$, fusiform in $24 \%$, and dissecting in $14 \% .{ }^{6}$ Symptoms vary and may include hypertension, pain, hematuria, and renal infarction; ${ }^{7}$ however, most patients are

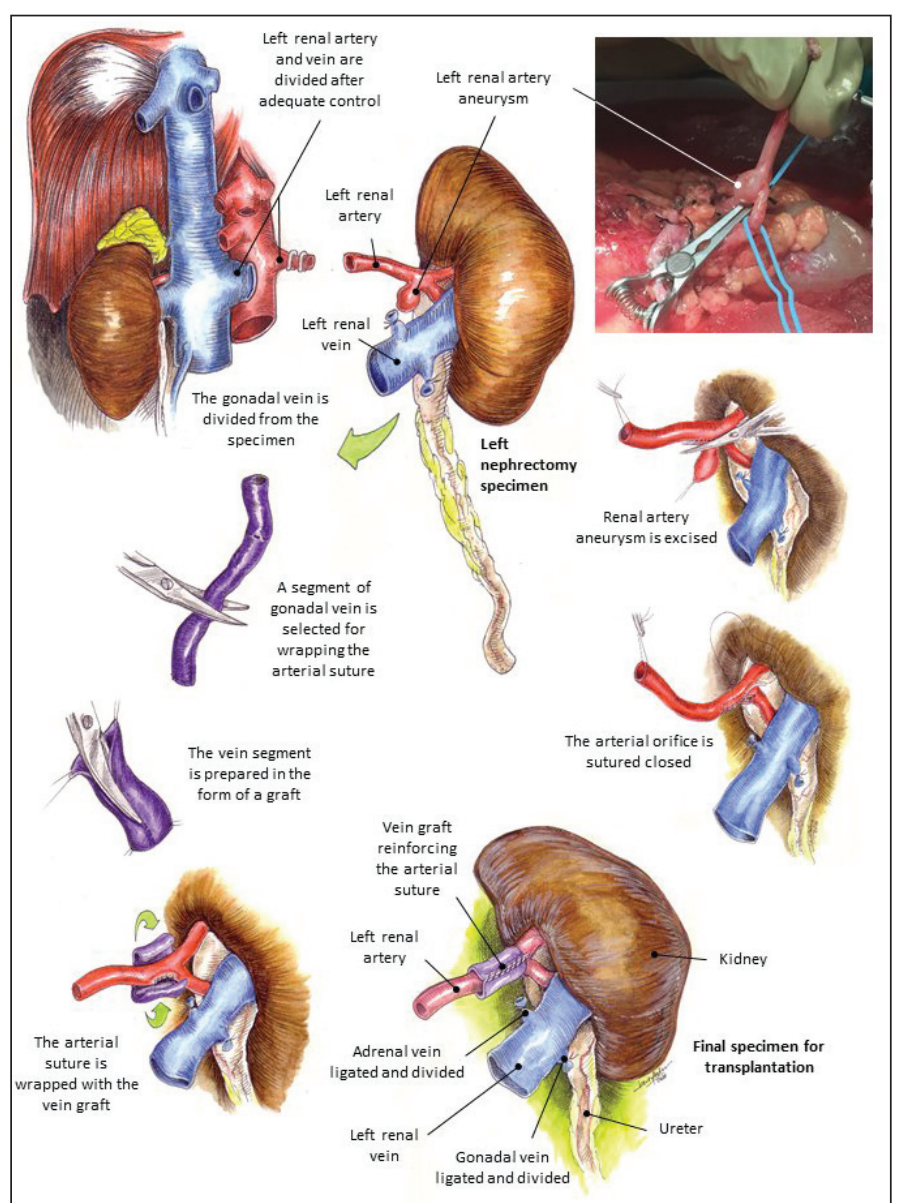

Fig. 4. Steps of the donor gonadal vein utilization to reinforce the reconstructed renal artery after excision of the aneurysm.

asymptomatic and lesions are benign. Pregnancy is associated with a higher rate of rupture. ${ }^{8}$ The potential risk for rupture lies with increasing size of aneurysms. ${ }^{9}$ Different surgical approaches are available for reconstruction of a RAA depending on its morphology and location. Fusiform aneurysms are usually repaired using aneurysmal segment excision and vascular bypass technique. With the saccular type, the repair of choice is tangential excision and primary repair or patch angioplasty if the aneurysmal neck is wide., In our cohort, the aneurysm was the saccular type, which was excised and repaired primarily. None of them required patch angioplasty. Currently, there is no consensus about the size at which an RAA should be surgically repaired in an asymptomatic patient, but experts have recommended RAA elective repair at diameters ranging from $1.5-3 \mathrm{~cm}^{3}$

The shortage of organs has resulted in increasing the use of so-called marginal kidneys from living donors with anatomical anomalies and even kidneys with small malignant tumours. ${ }^{10}$ The reported series on transplantation from living donors with RAA are small and from a single centre. Jung et al reported two cases with RAA that were $2 \mathrm{~cm}$ and 2.4 
Alameddine et al.

\begin{tabular}{|c|c|c|c|c|}
\hline Case & Age (years) & Gender & Side & Size of aneurysm $(\mathrm{mm})$ \\
\hline 1 & 53 & M & Right & 11 \\
\hline 2 & 22 & $\mathrm{~F}$ & Right & 5.5 \\
\hline 3 & 54 & $\mathrm{~F}$ & Left & 8 \\
\hline 4 & 49 & M & Right & 5 \\
\hline
\end{tabular}

$\mathrm{cm}$ in size. ${ }^{11}$ Patients underwent hand-assisted laparoscopic donor nephrectomies and ex-vivo reconstruction ensued. The allografts worked well immediately postoperative, but no long-term outcomes were recorded. ${ }^{11}$ Nahas et al reported 11 recipients from donors with vascular abnormalities, including three RAA cases, after open nephrectomy and ex-vivo reconstruction. ${ }^{12}$ One patient had arterial thrombosis at 55 months; the other two had a mean followup of 133 months with good renal function. ${ }^{12}$ Olakkengil in his study reported four living donors with RAA who had a mean followup of 3.5 years (range 1.9-8)..$^{13}$ The followup of donors included annual USD of the remaining kidney and renal function. He recommended following donors to look for an incidence of RAA in the opposite kidney, ${ }^{13}$ as Dzsinich reported bilaterality of RAA in $3.1 \%{ }^{3}$

The laparoscopic approach has been shown to be the procedure of choice for living donor nephrectomy in terms of recovery time, analgesic requirement, and length of hospital stay. ${ }^{14}$ We used the hand-assisted technique, as it possesses better exposure and handling of tissues, especially in cases with vascular pathology. All our patients are doing well. Both renal function and USD remain within normal range.

In fact, donors with renovascular lesions are rarely encountered $(0.006 \%$ over six years in our cohort). The selection of those kidneys is still controversial. Literature reports only a handful of case series. Our study involves several limitations. It is a retrospective case series of small sample size with a short followup period. More patients need to be enrolled with a longer followup to better understand the long-term consequences of this scenario in both recipients and donors.

\section{Conclusion}

Using kidneys with RAA for transplantation is safe and efficient. This may play an important role in expanding the donor pool. Closer followup of both donors with RAA and the recipients receiving these kidneys after repair is necessary. Also, removing those kidneys may be beneficial to the donors who are at higher risk of aneurysm progression and rupture. Furthermore, we recommend the hand-assisted laparoscopic approach for donor nephrectomy in this situation for better visualization.

Competing interests: The authors report no competing personal or financial interests.

\begin{tabular}{|c|c|c|c|c|c|}
\hline \multirow[b]{2}{*}{ Case } & \multirow[b]{2}{*}{$\begin{array}{c}\text { Age } \\
\text { (years) }\end{array}$} & \multirow[b]{2}{*}{$\begin{array}{l}\text { Relation } \\
\text { to donor }\end{array}$} & \multirow{2}{*}{$\begin{array}{l}\text { Followup } \\
\text { US duplex }\end{array}$} & \multirow{2}{*}{$\begin{array}{c}\text { eGFR at } 1 \\
\text { year }(\mathrm{mL} / \\
\mathrm{min} / 1.73 \\
\left.\mathrm{~m}^{2}\right)\end{array}$} & \multirow[b]{2}{*}{ Complication } \\
\hline & & & & & \\
\hline 1 & 45 & Unrelated & $\begin{array}{c}4 \text { years } \\
\text { Patent } \\
\text { renal artery }\end{array}$ & 53.47 & $\begin{array}{l}\text { Mild wound } \\
\text { infection }\end{array}$ \\
\hline 2 & 3 & Unrelated & $\begin{array}{c}3 \text { years } \\
\text { Patent } \\
\text { renal artery }\end{array}$ & 199 & None \\
\hline 3 & 40 & Unrelated & $\begin{array}{c}2 \text { years } \\
\text { Patent } \\
\text { renal artery }\end{array}$ & 56.13 & None \\
\hline 4 & 27 & Son & $\begin{array}{c}1 \text { year } \\
\text { Patent } \\
\text { renal artery }\end{array}$ & 4 & AMR \\
\hline
\end{tabular}

AMR: antibody-mediated rejection; eGFR: estimated glomerular filtration rate; US: ultrasound.

This paper has been peer-reviewed.

\section{References}

1. Zhang $L$, Yang GF, Qi J, et al. Renal artery aneurysm: Diagnosis and surveillance with multidetector row computed tomography. Acta Radiologica 2007;48:274-9. https://doi.org/10.1080/02841850601161521

2. Seppala FE, Levey J. Renal artery aneurysm: Case report of a ruptured calcified renal artery aneurysm. American Surg 1982;48:42-4.

3. Dzsinich C, Gloviczki P, McKusick MA, et al. Surgical management of renal artery aneurysm. Cardiovasc Surg 1993; 1:243-7.

4. Matas AJ, Smith JM, Skeans MA, et al. OPTN/SRTR 2013 annual data report: Kidney. Am J Transplant 2015;15 Suppl 2:1-34. https://doi.org/10.1111/ajt.13195

5. Dulabon $L M$, Singh A, Vogel $F$, et al. Intrarenal pseudoaneurysm presenting with microscopic hematuria and right flank pain. Can J Urol 2007;14:3588-91.

6. Bastounis E, Pikoulis E, Georgopoulos $S$, et al. Surgery for renal artery aneurysms: A combined series of two large centres. Eur Urol 1998;33:22-7. https://doi.org/10.1159/000019530

7. Rautio R, Haapanen $A$. Transcatheter embolization of a renal artery aneurysm using ethylene vinyl alcohol copolymer. Cardiovasc Intervent Radiol 2007;3:300-3. https://doi.org/10.1007/s00270-005-0238-2

8. Tham $\mathrm{G}$, Ekelund L, Herrlin $\mathrm{K}$, et al. Renal artery aneurysms. Natural history and prognosis. Ann Surg1983;197:348-52. https://doi.org/10.1097/00000658-198303000-00016

9. Silver PR, Budin JA. Unusual manifestations of renal artery aneurysms. Urol Radiol 1990;12:80-3. https://doi.org/10.1007/BF02923973

10. Lugo-Baruqui JA, Guerra $G$, Chen $L$, et al. Living donor renal transplantation with incidental renal cell carcinoma from donor allograft. Transpl Int 2015;28:1126-30. https://doi.org/10.1111/tri.12594

11. Jung CW, Park KT, Kim MG. Experiences of renal transplants from donors with a renal artery aneurysm after a laparoscopic donor nephrectomy and ex vivo reconstruction of the renal artery. Exp Clin Transplant 2013;11:324-6. https://doi.org/10.6002/ect.2013.0023

12. Nahas WC, Lucon AM, Mazzucchi E, et al. Kidney transplantation: The use of living donors with renal artery lesions. J Urol 1998;160:1244-7. hitps://doi.org/10.1016/S0022-5347(01)62508-4

13. Olakkengil SA, Mohan Rao M. Transplantation of kidneys with renal artery aneurysm. Clin Transplant 2011;25:E516-9. https://doi.org/10.1111/i.1399-0012.2011.01460.x

14. Shirodkar SP, Bird V, Velazquez 0 , et al. Novel management of complicated renal artery aneurysm: Laparoscopic nephrectomy and ex-vivo repair with heterotopic autotransplant. J Endourol 2010;24:35-9. htrps://doi.org/10.1089/end.2009.0338

Correspondence: Dr. Mahmoud Alameddine, Department of Transplant Surgery, University of Miami Miller School of Medicine, Miami, FL, United States; dralameddine@hotmail.com 